\title{
DOSES E FORMAS DE APLICAÇÃO DE BIOESTIMULANTE NA PRODUÇÃO DE MUDAS DE MARACUJAZEIRO
}

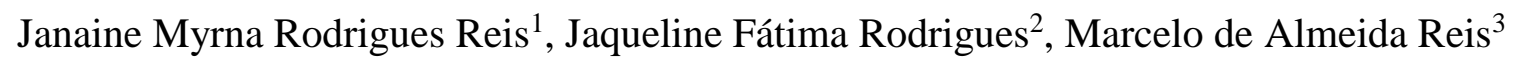

${ }^{1}$ Professora Adjunto III do Curso de Agronomia, Fitotecnia, Centro Universitário de Patos de Minas/UNIPAM, Patos de Minas (MG)

${ }^{2}$ Professora Adjunto IV do Curso de Agronomia, Ciência do Solo, Universidade Federal de Goiás/UFG, Regional Jataí, Jataí (GO)

${ }^{3}$ Professor do Curso de Agronomia, Fitotecnia, Faculdade Cidade de Coromandel/FCC, Coromandel (MG)

RESUMO: O uso de bioestimulantes é uma das maneiras de se buscar mudas de qualidade e em menor tempo. Com o objetivo de avaliar a ação de bioestimulante na formação de mudas de maracujazeiro sob diferentes formas de aplicação, o experimento foi conduzido na cidade de Patos de Minas-MG, no período de abril a junho, em estufa, trabalhando-se com sementes de maracujazeiro amarelo em saquinhos de polietileno de $10 \mathrm{~cm}$ de largura e $17 \mathrm{~cm}$ de altura. $\mathrm{O}$ delineamento experimental utilizado foi inteiramente casualizado com sete tratamentos, três repetições e oito saquinhos de polietileno por parcela contendo uma muda cada. Os tratamentos foram a aplicação de três doses $\left(10,15,20 \mathrm{~mL} \mathrm{Kg}^{-1}\right)$ via semente e três doses $\left(100,125,150 \mathrm{~mL} \mathrm{~L}^{-1}\right)$ via foliar do bioestimulante Stimulate ${ }^{\circledR}$, além da testemunha. Aos 60 dias após a emergência avaliou-se a altura das mudas (AM), massa da matéria seca das raízes (MSR) e da parte aérea (MSPA) de quatro mudas de cada tratamento. As quatro mudas restantes foram conduzidas até atingirem $25 \mathrm{~cm}$ de altura, variável chamada de número de dias para ir a campo (DC). Os dados foram submetidos a análise de variância e comparados pelo teste de Tukey, a $5 \%$ de probabilidade. Os tratamentos não influenciaram significativamente as variáveis AM, MSR e MSPA. A aplicação do bioestimulante Stimulate ${ }^{\circledR}$ via foliar se mostrou eficiente na variável número de dias para ir a campo, independente da dose aplicada.

Palavras-chave: Passiflora edulis Sims. f. flavicarpa Degener. Crescimento. Propagação.

\section{BIOSTIMULANT APPLICATION RATES AND METHODS USED IN THE PRODUCTION OF PASSION FRUIT SEEDLINGS}

\begin{abstract}
Biostimulants can be used to produce quality seedlings in less time. With the objective of evaluation the action of biostimulant on the formation of seedlings of passion fruit under different forms of application, the present experiment was conducted in the city of Patos de Minas-MG, in the period from April to June, in a greenhouse by sowing yellow passion fruit seeds in polyethylene bags $(10 \mathrm{~cm}$ wide $\mathrm{x} 17 \mathrm{~cm}$ high). The experimental design was completely randomized with seven treatments, three replicates and eight bags per plot containing one seedling each. The treatments consisted of a control, three application rates $\left(10,15,20 \mathrm{ml} \mathrm{Kg}^{-1}\right)$ via the seeds and three foliar application rates $\left(100,125,150 \mathrm{ml} \mathrm{L}^{-1}\right)$ of the biostimulant, Stimulate ${ }^{\circledR}$. Sixty days after emergence, seedling height (SH), root dry matter (RDM) and shoot dry matter (SDM) were measured for four seedlings from each
\end{abstract}

Cultura Agronômica, Ilha Solteira, v.25, n.3, p.267-274, 2016 
treatment. The remaining four seedlings were grown to a height of $25 \mathrm{~cm}$. The time needed for this is called the number of days to field (DF). The data were submitted to analysis of variance and compared by the Tukey test at the 5\% probability level. The treatments did not influence AM, MSR and MSPA variables. Foliar applications of the biostimulant Stimulate ${ }^{\circledR}$ efficiently reduced the number of days to field regardless of application rate.

Key words: Passiflora edulis Sims. f. flavicarpa Degener. Growth. Propagation.

\section{INTRODUÇÃO}

O maracujazeiro é uma planta de clima tropical com mais de 150 espécies de Passifloraceas utilizadas para consumo humano e uma das espécies mais cultivadas no Brasil e no mundo é o maracujá-amarelo (Passiflora edulis f. flavicarpa Deg) (CEPLAC, 2015), também conhecido como azedo. O maracujá é uma cultura em franca expansão com o Brasil em primeiro lugar na produção mundial (EMBRAPA, 2015), com área plantada de 59.246 ha e produção estimada de 776.097 toneladas segundo o último levantamento agrícola disponível (IBGE, 2012). O maracujá amarelo, o mais consumido na forma de sucos, foi considerado uma fruta de pomar doméstico durante muitos anos, em razão de suas propriedades medicinais (MELETTI, 2011).

A propagação do maracujazeiro pode ser sexuada ou vegetativa (estaquia e enxertia) e o cultivo 'in vitro'. O método usualmente utilizado no estabelecimento de pomares comerciais é o de mudas formadas a partir de sementes (propagação sexual) devido ao menor custo de produção (LEONEL; PEDROSO, 2005) e a obtenção de plantas mais vigorosas. Para Braga e Junqueira (2003), a propagação por sementes é a mais usual para se fazer mudas de maracujá por ser simples e econômica. No entanto, este sistema de produção apresenta elevada desuniformidade entre as mudas, o que é considerado um ponto negativo.

A propagação sexual na produção de mudas pode ser feito através de semeadura em bandejas, necessitando de transplantio posterior ou diretamente nos recipientes onde permanecerão até irem para o campo. A produção de mudas através da semeadura direta nos recipientes proporciona melhor aproveitamento das sementes e da área de produção, além de reduzir o estresse por ocasião do transplantio. De acordo com Minami (1995), outro ponto importante é a redução do tempo de produção das mudas, visto que quanto mais rápida a muda é produzida menores custos são gastos com insumos e mão-de-obra.

A produção de mudas constitui-se em uma das etapas mais importantes do sistema produtivo, influenciando diretamente no desempenho da planta. Assim, para o sucesso da instalação de um pomar de frutíferas é necessário o uso de mudas de alta qualidade, homogêneas, de rápida formação e com precocidade na produção (NATALE et al., 2004). Considera-se que $60 \%$ do sucesso de uma cultura, estão em implantá-la com mudas de alta qualidade (MINAMI, 1995).

Com a constatação dos benefícios dos hormônios ou reguladores vegetais sobre as plantas cultivadas, muitos compostos e combinações desses produtos têm sido pesquisados

Cultura Agronômica, Ilha Solteira, v.25, n.3, p.267-274, 2016 
com a finalidade de resolver problemas do sistema de produção (CASTRO; VIEIRA, 2001), como contornar inconvenientes do acamamento de algumas culturas (MARCO JÚNIOR et al., 2013).

De acordo com Taiz e Zeiger (2004), os hormônios vegetais podem ser divididos em dois grupos: os estimuladores do crescimento (auxinas, giberelinas e citocininas) e os inibidores do crescimento (etileno e ácido abscísico). Devido aos efeitos adicionais dos reguladores vegetais que promovem o crescimento e desenvolvimento das plantas, é crescente a utilização de produtos denominados bioestimulantes, que Castro e Vieira (2001) definem como sendo a mistura de dois ou mais reguladores vegetais com outras substâncias como aminoácidos, nutrientes, vitaminas, dentre outros. Atualmente, as pesquisas têm apontado para a utilização de produtos que apresentem em sua composição mais de um regulador vegetal, como é o caso dos bioestimulantes (TAIZ; ZEIGER, 2004).

Segundo os mesmos autores, as giberelinas presentes nos bioestimulantes têm ação na síntese de proteínas e RNA específicos na germinação, tanto na quebra da dormência como no controle da hidrólise de reservas, da qual depende o embrião em crescimento. Já as citocininas, derivadas da adenina, caracterizam-se pela habilidade em induzir a divisão celular e as auxinas têm a função principal de regular o alongamento das células vegetais, induzir a formação do sistema radicular, entre outras.

O emprego de bioestimulantes tem otimizado os processos fisiológicos de germinação e crescimento das mudas em várias espécies (PIEREZAN et al., 2012) e sua aplicação pode ser via semente ou através de pulverizações foliares. De acordo com LANA et al. (2009), técnicas que induzem à maior germinação e qualidade fisiológica são fatores importantes para aumentar o potencial de desempenho das sementes e, consequentemente, a uniformidade das plantas no campo. Segundo os mesmos autores, a aplicação de bioestimulantes nos primeiros estágios de desenvolvimento da planta estimula o crescimento radicular, proporcionando recuperação mais rápida após estresse hídrico, maior resistência a insetos, pragas, doenças e nematoides, estabelecimento mais rápido e uniforme das plantas, favorecendo a produção.

O objetivo do presente estudo foi avaliar a ação de bioestimulante na formação de mudas de maracujazeiro amarelo sob diferentes formas de aplicação.

\section{MATERIAL E MÉTODOS}

O experimento foi conduzido no período de abril a junho, no município de Patos de Minas-MG, situado a $842 \mathrm{~m}$ de altitude, $18^{\circ} 34^{\prime} 46^{\prime \prime} \mathrm{S}$ e 463'6" $\mathrm{W}$, na microrregião do Alto Paranaíba mineiro.

Trabalhou-se em estufa coberta com filme de polietileno transparente e protegida lateralmente com sombrite. Utilizou-se sementes de maracujazeiro amarelo (Passiflora edulis Sims $f$. flavicarpa Deg) obtidas de frutos colhidos em campo de produção, obedecendo os critérios relativos à maturação fisiológica e à qualidade comercial.

O delineamento experimental utilizado foi o inteiramente casualizado (DIC), com sete tratamentos e três repetições, contabilizando vinte e uma unidades experimentais. Cada Cultura Agronômica, Ilha Solteira, v.25, n.3, p.267-274, 2016 
unidade experimental foi representada por oito saquinhos de polietileno com capacidade de $482 \mathrm{~mL}$, totalizando 168 plantas. Os saquinhos foram preenchidos com o substrato comercial Bioplant@, cuja matéria prima principal é a casca de pinus.

Os tratamentos testados foram aplicações via semente (VS) e via foliar (VF) do bioestimulante comercial Stimulate ${ }^{\circledR}$ que é composto por três reguladores vegetais (citocinina, giberelina e auxina) em diferentes doses. Os tratamentos foram: T1 (Testemunha); T2 (VS $10 \mathrm{~mL} \mathrm{Kg}^{-1}$ de sementes); T3 (VS $15 \mathrm{~mL} \mathrm{Kg}^{-1}$ de sementes); T4 (VS $20 \mathrm{~mL} \mathrm{Kg}{ }^{-1} \mathrm{de}^{-}$ sementes); T5 (VF $100 \mathrm{~mL} \mathrm{~L}^{-1}$ ); T6 (VF $125 \mathrm{~mL} \mathrm{~L}^{-1}$ ); T7 (VF $150 \mathrm{~mL} \mathrm{~L}^{-1}$ ). As doses dos tratamentos foram determinadas em virtude de dados do uso de bioestimulante pesquisados na literatura.

Nos tratamentos VS as doses do bioestimulante foram aplicadas diretamente sobre as sementes acondicionadas em sacos plásticos com o auxílio de uma pipeta graduada. O saco plástico de cada tratamento contendo as sementes foi agitado até que todas entrassem em contato com o produto. Em seguida, as sementes foram colocadas para secar a sombra durante uma hora. Nos tratamentos VF, cada dose do bioestimulante foi aplicada em uma única pulverização quando as mudas atingiram cinco $\mathrm{cm}$ de altura e realizada no fim da tarde, quando a temperatura já estava amena.

A semeadura foi realizada com três sementes em cada saquinho e quando as plantas atingiram três $\mathrm{cm}$ de altura, foi feito o desbaste deixando somente uma planta por recipiente. Aos 60 dias após a emergência (DAE), coletaram-se quatro mudas por tratamento e avaliouse a altura das mudas (AM), massa seca das raízes (MSR) e da parte aérea (MSPA). Para determinação da altura das mudas, utilizou-se uma régua graduada em centímetro, tomando como referência a distância do colo ao ápice da muda. Para a determinação da biomassa seca do sistema radicular e da parte aérea foi utilizada a secagem em estufa de circulação forçada a $60^{\circ} \mathrm{C}$, até atingirem peso constante. Os materiais obtidos foram pesados em balança analítica.

Foram conduzidas as quatro mudas restantes de cada tratamento para a avaliação do número de dias para ir a campo (DC), que foi determinado quando as plantas atingiram 25 centímetros de altura. Segundo São José (1994), citado por Verdial et al. (2000), uma boa muda de maracujá deve ter pelo menos $25 \mathrm{~cm}$ de altura, dentre outras características, para poder ser transplantada.

Os dados foram submetidos a análise de variância e comparados pelo teste de Tukey a $5 \%$ de probabilidade. As análises foram realizadas pelo programa computacional SISVAR.

\section{RESULTADOS E DISCUSSÃO}

As análises estatísticas mostraram-se não significativas para as variáveis estudadas, com exceção da avaliação do número de dias necessários para ir a campo (DC). A Tabela 1 apresenta os valores médios encontrados para as variáveis estudadas.

Cultura Agronômica, Ilha Solteira, v.25, n.3, p.267-274, 2016 
Tabela 1. Avaliação da altura das mudas (AM), massa seca da parte aérea (MSPA), massa seca das raízes (MSR) e dias para ir a campo (DC) das mudas de maracujá amarelo submetidas à diferentes formas de aplicações e doses do bioestimulante Stimulate®.

\begin{tabular}{ccccc}
\hline Tratamentos & $\begin{array}{c}\text { AM } \\
(\mathrm{cm})\end{array}$ & $\begin{array}{c}\text { MSPA } \\
(\mathrm{g})\end{array}$ & $\begin{array}{c}\text { MSR } \\
(\mathrm{g})\end{array}$ & $\begin{array}{c}\text { DC } \\
(\text { dias })\end{array}$ \\
\hline T1 & $9,79 \mathrm{a}$ & $0,58 \mathrm{a}$ & $0,17 \mathrm{a}$ & $83 \mathrm{a}$ \\
T2 & $11,70 \mathrm{a}$ & $0,68 \mathrm{a}$ & $0,20 \mathrm{a}$ & $75 \mathrm{~b}$ \\
T3 & $10,72 \mathrm{a}$ & $0,57 \mathrm{a}$ & $0,23 \mathrm{a}$ & $75 \quad \mathrm{~b}$ \\
T4 & $9,41 \mathrm{a}$ & $0,36 \mathrm{a}$ & $0,26 \mathrm{a}$ & $83 \mathrm{a}$ \\
T5 & $10.97 \mathrm{a}$ & $0,57 \mathrm{a}$ & $0,14 \mathrm{a}$ & $71 \quad \mathrm{c}$ \\
T6 & $10,72 \mathrm{a}$ & $0,57 \mathrm{a}$ & $0,18 \mathrm{a}$ & $72 \quad \mathrm{c}$ \\
T7 & $11,80 \mathrm{a}$ & $0,61 \mathrm{a}$ & $0,17 \mathrm{a}$ & $71 \quad \mathrm{c}$ \\
\hline C.V. (\%) & 9,11 & 22,22 & 26,05 & 1,41 \\
Média Geral & 10,73 & 0,56 & 0,19 & 75,71 \\
\hline
\end{tabular}

Médias seguidas de mesma letra na coluna não diferem entre si, pelo teste de Tukey, a 5\% de probabilidade. Tratamentos: T1 (Testemunha); T2 (VS $10 \mathrm{~mL} \mathrm{Kg}^{-1}$ de sementes); T3 (VS $15 \mathrm{~mL} \mathrm{Kg}^{-1}$ de sementes); T4 (VS 20 $\mathrm{mL} \mathrm{Kg}^{-1}$ de sementes); T5 (VF $100 \mathrm{~mL} \mathrm{~L}^{-1}$ ); T6 (VF $125 \mathrm{~mL} \mathrm{~L}^{-1}$ ); T7 (VF $150 \mathrm{~mL} \mathrm{~L}^{-1}$ ).

A variável AM teve valores que foram de 9,41 a 11,80 cm, com valor médio de 10,73 $\mathrm{cm}$ aos 60 DAE, não se verificando uma tendência de comportamento entre as formas de aplicação e as doses de bioestimulante. Os dados corroboram com o trabalho de Echer et al. (2006), que ao estudarem cinco doses de bioestimulante aplicadas via semente em maracujazeiro amarelo, relatam que não encontram evidências de resposta do produto na variável altura de mudas aos 50 dias após emergência, obtendo um valor médio de $12 \mathrm{~cm}$ de altura. Para Verdial et al. (2000), o tamanho da muda de maracujazeiro amarelo influencia o desenvolvimento inicial das mesmas, sendo que mudas maiores tendem a formar plantas mais desenvolvidas.

Embora não tenha havido diferença estatística significativa para a variável massa seca da parte aérea (MSPA), obteve-se um valor médio de $0,56 \mathrm{~g}$, com o menor valor $(0,36 \mathrm{~g})$ e o maior valor $(0,68 \mathrm{~g})$ alcançados nos tratamentos em que o bioestimulante foi aplicado via semente nas doses de $20 \mathrm{~mL} \mathrm{Kg}^{-1}$ e $10 \mathrm{~mL} \mathrm{Kg}^{-1}$, respectivamente.

A massa seca das raízes (MSR) apresentou um valor médio de 0,19 g. Os menores valores foram obtidos quando foi feita a aplicação do bioestimulante via foliar, equivalendose a testemunha. Contrariando esses resultados, Echer et al. (2006), observaram resposta positiva do bioestimulante, quando comparado à testemunha, no incremento da massa seca da parte aérea e raízes, durante o desenvolvimento das mudas de maracujazeiro amarelo, com maior eficiência na dose de $4 \mathrm{~mL}$ por $\mathrm{Kg}$ de sementes para a biomassa seca das raízes.

Os resultados não significativos para as variáveis AM, MSR e MSPA avaliadas aos 60 DAE, pode indicar que esse período de tempo não foi suficiente para a resposta ao bioestimulante, embora tenham havido diferenças entre os tratamentos.

Observa-se que não houve correlação entre as respostas para a produção de massa seca das raízes e da parte aérea.

Cultura Agronômica, Ilha Solteira, v.25, n.3, p.267-274, 2016 
Encontrou-se como média que seriam necessários 75,71 dias para que as mudas atingissem $25 \mathrm{~cm}$ para poderem ir para o campo (DC). Lembrando que o menor número de dias para a muda alcançar $25 \mathrm{~cm}$ é o ideal, esse foi de 71 dias observados na aplicação via foliar (VF) nas doses de $100 \mathrm{ml} \mathrm{L}^{-1}$ e $150 \mathrm{ml} \mathrm{L}^{-1}$ de bioestimulante, seguida da dose $125 \mathrm{~mL}$ $\mathrm{L}^{-1}$, sem diferenças estatísticas entre elas.

O período mais longo, ou seja, quando se necessitou de mais dias para as mudas alcançarem $25 \mathrm{~cm}$ de altura foi na testemunha que não recebeu bioestimulante e na aplicação via semente da dose de $20 \mathrm{~mL} \mathrm{Kg}^{-1}$. Ferrari et al. (2007), ao estudarem o crescimento de mudas de maracujazeiro-doce com aplicações de doses de biostimulantes via foliar, encontraram uma taxa de crescimento mais elevada na dose de $125 \mathrm{~mL} \mathrm{~L}^{-1}$. No entanto, Castro et al. (1985), citados por Lana et al. (2009), relatam que a aplicação de fitohormônio via semente é mais eficaz que a aplicação via foliar, além de evitar a fitotoxidade destes produtos quando aplicados tardiamente. .

Embora não tenha havido diferenças significativas entre as formas de aplicação e doses até os $60 \mathrm{DAE}$, observa-se que as mudas que receberam o bioestimulante via foliar tiveram um adiantamento no crescimento, permitindo que a muda estivesse pronta para o plantio em um menor tempo. Segundo Natale et al. (2004), esta resposta é interessante pela obtenção de mudas em menor tempo, refletindo em economia de área e insumos por possibilitar uma rápida implantação do pomar, acelerando o retorno financeiro.

Segundo Echer et al. (2006), na produção de mudas de alta qualidade busca-se um menor tempo de formação além de outras características ligadas à anatomia da planta, influenciando na taxa de pegamento das mesmas no campo, após o transplante.

\section{CONCLUSÃO}

As doses e formas de aplicação do bioestimulante Stimulate ${ }^{\circledR}$ não influenciaram significativamente a altura das mudas e as massas secas da raiz e da parte aérea.

O biostimulante Stimulate ${ }^{\circledR}$ aplicado via foliar, nas doses de 100,125 ou $150 \mathrm{~mL} \mathrm{~L}^{-1}$, proporcionou a produção mais rápida de mudas de maracujazeiro amarelo em relação à aplicação via semente.

\section{REFERÊNCIAS BIBLIOGRÁFICAS}

BRAGA, M. F.; JUNQUEIRA, N. T. Produção de mudas de maracujá-doce. Planaltina: Embrapa Cerrados, 2003. 28 p. (Embrapa Cerrados. Documentos, 93).

CASTRO, P. R. E.; VIEIRA, E. L. Aplicações de reguladores vegetais na agricultura tropical. Guaíba: Agropecuária, 2001. 131 p.

CEPLAC. Maracujá. 2015. Disponível em: http://www.ceplac.gov.br/radar/maracujá.htm. Acesso em: 07 ago. 2015. 
ECHER, M. M.; GUIMARÃES, V. F.; KRIESER, C. R.; ABUCARMA, V. M.; KLEIN, J.; SANTOS, L.; DALLABRIDA, W. R. Uso de bioestimulante na formação de mudas de maracujazeiro amarelo. Semina: Ciências Agrárias, Londrina, v. 27, n. 3, p.351-360, 2006.

EMBRAPA. Maracujá. 2015. Disponível em: http://www.embrapa.br/mandioca-efruticultura/cultivos/maracuja.htm. Acesso em: 07 ago. 2015.

FERRARI, T. B.; FERREIRA, G.; BOARO, C. S. F.; ZUCARELI, V. Bioestimulante no crescimento de plântulas de maracujazeiro-doce. Revista Brasileira de Biociências, Porto Alegre, v. 5, supl. 2, p.342-344, 2007.

IBGE - Instituto Brasileiro de Geografia e Estatística. Produção Agrícola Municipal culturas temporárias e permanentes. Rio de Janeiro, 2012. Disponível em: http://www.ibge.gov.br/home/estatistica/economia/pam/2012/default_temp_perm_xlx.shtm. Acesso em: 05 set. 2016.

LANA, A. M. Q.; LANA, R. M. Q.; GOZUEN, C. F.; BONOTTO, I.; TREVISAN, L. R. Aplicação de reguladores de crescimento na cultura do feijoeiro. Biosciencie Journal, Uberlândia, v. 25, n. 1, p.13-20, 2009.

LEONEL, S.; PEDROSO, C. J. Produção de mudas de maracujazeiro doce com uso de biorregulador. Revista Brasileira de Fruticultura, Jaboticabal, v. 27, n. 1, p.107-119, 2005.

MARCO JÚNIOR, J.; CORREA, D.; NAKAI, C. H. Efeito do regulador de crescimento trinexapac-ethyl na produtividade de trigo. Acta Iguazu, Cascavel, v. 2, n. 1, p.14-19, 2013.

MELETTI, L. M. M. Avanços na cultura do maracujá no Brasil. Revista Brasileira de Fruticultura, Jaboticabal, v. 33, n. 1, p.83-91, 2011.

MINAMI, K. Produção de mudas de alta qualidade. São Paulo: T.A. Queiroz, 1995. 135 p.

NATALE, W.; PRADO, R. M.; LEAL, R. M.; FRANCO, C. F. Efeitos da aplicação de zinco no desenvolvimento, no estado nutricional e na produção de matéria seca de mudas de maracujazeiro. Revista Brasileira de Fruticultura, Jaboticabal, v. 26, n. 2, p.310-314, 2004. PIEREZAN, L.; SCALON, S. P. Q.; PEREIRA, Z. V. Emergência de plântulas e crescimento de mudas de jatobá com uso de bioestimulante e sombreamento. Cerne, Lavras, v. 18, n. 1, p.127-133, 2012.

TAIZ, L.; ZEIGER, E. Fisiologia vegetal. Porto Alegre, Artmed Editora S.A., 2004. 719 p.

VERDIAL, M. F.; LIMA, M. S.; TESSARIOLI NETO, J. Métodos de formação de mudas de maracujazeiro amarelo. Scientia Agrícola, Piracicaba, v. 57, n. 4, p.795-798, 2000.

Cultura Agronômica, Ilha Solteira, v.25, n.3, p.267-274, 2016 
